\title{
AN OVERVIEW OF THE DEVELOPMENTAL STAGES IN CHILDREN'S DRAWINGS \\ Jeralyn Hufford
}

The primary emphasis in this paper will be to investigate the development of drawing in young children and a possible relationship between this development and various art related elements such as creativity and expression. Emphasis will lie with the stages and development in the drawings of children, but through the analys is of the stages, aspects which seem to lend themselves to utilization of creative or expressive qualities will be singled out. Even though there are certain developmental stages of children's art which appear to be quite natural or sequential if allowed to develop, there are times at which the experience could be enhanced in such a way that the subsequent qualities of creativity and expressiveness could be encouraged.

Through looking at the drawings of children one can gain new ways of seeing, understanding, testing and verifying ideas that are indicative of the nature of thought and problem-solving. Since a great deal of thinking and communicating takes place visually, analysis of the drawing process can begin to lend itself to the understanding of "how we know" or process certain information (Goodnow, 1977).

According to Goodnow there are three lines of study that lend themselves to the application of understanding children's drawings, these are: the analysis of patterns, attention to sequence, and study of questions of equivalence or the nature of same and different.

There is a relationship between visual elements such as dots, lines, circles, squares, blobs, masses, etc. as they appear in the drawings of children. Depending upon the readiness of the child there will be a variety of solutions dealing with the arrangement of these visual elements to produce a sense of balance, unity, rhythm, movement, or surprise. Arrangement or composition is also dependent upon the choice a child makes in placing pattern around a reference point, multiple relationships, or the boundaries that exist visually or behaviorally within the child or her drawing.

The sequence that occurs in the drawings of children refers to a routine in the placement or making of visual elements. At times children will set constraints for themselves and the ability to recognize this aspect of the drawing process lends itself to the understanding of features in the drawing. Constraints have to do with the way children see later parts of a drawing keeping in relationship with earlier parts of the drawing. It appears that this is a method of learning to depict visually some thing with a safety net thrown in, so to speak.

In conjunction with Piaget's developmental theories it should be 
noted that he acknowledges an interaction between the child and his environment--out of the interactions develop structures of thought, each one more complex, and more inclusive than the previous one (Pulaski, 1971).

For Piaget adaptation or the ability to organize sensations and experiences into a semblance of order is of a dual nature. The duality consists of assimilation which is defined for Piaget's purpose as the taking in process by which one incorporates things, and accommodation which is the adjusting process of reaching out to the environment. For Piaget these two processes function simultaneously.

The child's mind seeks equilibrium between what is understood and experienced in the environment. The process of equilibrium, attaining a balance between assimilation and accommodation, is considered the mechanism for growth and transition in cognitive development.

For Piaget as well as for Eleanor Gibson the baby is not seen as a passive organism, but as an active entity. Gibson (1969) felt that perceptual learning was functional, an interaction between the organism and the environment and that a modification of behavior was indicated because of the concern with learning; but because for her, perception was of primary concern, her investigations dealt with the ability of an organism to modify and extract information from the stimulation in the environment.

The phenomenal aspect of obtaining information from the physical world dealt with the awareness of events occurring in immediate surroundings, and the responsive aspect of perception entailed discrimination, a selective response to the environment (Gibson, 1969).

In the area of perception an increased ability to extract information from the environment is the result of experience, practice and interaction with the environment. In the area of cognitive development Piaget's second factor of experience helps to explain that aspect of cognitive development through a child's direct sensori-motor experiences that are encountered in ideal childhood situations. The uniqueness of experience both physical and empirical seems to play an important role in the readiness of children for the learning of a variety of tasks, and the perceptual development in children is related to the aspects of cognitive development and maturation.

Multiple relations in drawings, such as a chimney to a house, seem to depend upon the growth of Piaget's stages of operation which are concerned with the capacity to deal with change or transformation in one's mind rather than in physical reality.

Learning that symbols stand for or correspond to objects or events deals with the learning of equivalents. The invention of equivalents appears to be related to the modification of previously learned equivalents. The result being that children are actively engaged in observing the world, and in learning and abstracting rules and principles.

\section{Jeralyn Hufford 3}


One begins to gain some insight into how equivalents develop in children's drawings through observation of said drawings. It should be recognized that drawings are ambiguous and vary in their relationships as to what things stand for, but a particular equivalent can be requested and observations made as to how a problem of equivalence is solved (Goodnow, 1977). It appears that the underlying learning of equivalents is a matter of discovery and extension or modification of already known or available equivalents.

When drawings are analyzed according to pattern development a search for order is of the utmost concern. Design becomes an essential aspect in the child's drawing.

Drora Booth, who worked with Australian nursery school children, was able to divide pattern development into three categories:

scribble; topology, which was concerned with colors that were separated in masses or spots without clearly defined order; and pattern. The most common progression was from the scribble to topology to pattern stage of development, but shifts back and forth with color, idea, and techniques were explored. Between the use of 1 ines and dots, 7 ines were usually discovered first, and where repetition occurred, 1 ine was typically that mark first used (Goodnow, 1977).

An important aspect of Booth's observations was the cultural stress placed on realism versus decoration or the decorative unit in art. Perhaps this cultural preference for realism lends itself to the eventual development of certain art styles and that which is seemingly reinforced as "good art." Booth seemed to think that the invention of patterns should be understood in its own right.

In describing the units of children's drawings regarding organization the following criteria are of importance: repetition, economy, symmetry, rotation around a point, and arrangement to fit within certain proportions. The principles that underlie the arrangement of units are concerned with a search for order and balance, the effect of earlier stages, a preference for particular shapes and transformations, and the relative difficulty of transformations.

According to Goodnow children seem to operate with two general principles, one dealing with the importance of boundary within a drawing and the second concerned with the space involved in the drawing. "To each its own boundary" deals with embracing lines that depict an image not in just a series of units or parts, but as a means of presenting interacting relationships between parts. This is usually related to age and it is an intellectual and an artistic endeavor. Children move from early use of separate lines to the use of continuous or all embracing lines usually at the age of seven.

When children are utilizing all embracing 1 ines, the finished or completed drawing may appear to adult viewers to be bizarre, or they may misinterpret the child's drawing - - attributing to the drawing some psychological or emotional construct which really is not accurate. 
What in effect may have happened is that the child in trying to solve a visual and intellectual problem on paper has had to deal with the difficulty of anticipating problems that each new 7 ine has begun to create.

A very good point made by Goodnow is that of relating a drawing to intelligence, and the importance of being cognizant of the purpose of the child's drawing. In other words the observer should be careful when analyzing drawings and be as certain as possible that she is aware of the myriad of explanations that could be applied to the work before a final evaluation is made.

"To each its own space" is in effect a process concerned with problemsolving. When children decide to meet one goal they often have to sacrifice another, and the problem has been overcome by redefining the initial constraints.

The concept of sequence as it exists in children's drawings is evidenced by the order that is depicted. In pre-school age children there is a preference for a right-left sequence which seems to be related to writing.

A second order that is observed in drawings is the paired and radial sequences. The radial order is usually the earliest form, followed by the paired orders. Practice with shapes, an awareness of general body concepts, and the beginnings of general concepts about left and right are factors that should be kept in mind when deciphering children's work.

A third sequence that children utilize is that of top-to-bottom orders. These usually start with a circle which seems to come from experience: after the initial circle, the sequence follows a top-tobottom procedure and then a child often returns to add details. "Returning to details means that we have to overcome the sense of having finished. It also means that we have become adept at monitoring, at running a critical eye over a finished piece of work to see if all the pieces are there that should be there" (Goodnow, p. 55, 1977).

The final sequence is that of core to accessories. These sequences usually contain fairly large units in which more than one sequence exists. An example of this could be the body with clothing. Most children draw the body/figure first with the clothing drawn over the first phase of the drawing. The aspect of advanced planning in order that the figures woud not look like X-ray type drawings is usally not regarded as a solution: perhaps it is because they are unable to make the modification required in the standard drawing of the figure.

When children are working with shapes it becomes apparent that one shape can stand for something else. By exploring the question of "same" and "different" in drawings or equivalence researchers may gain some insight into how children learn about shapes as well as insight

\section{Jeralyn Hufford 5}


into some of the more general aspects of learning.

The shape of a mouth, the position of pupils, the placement of ground to sky, for instance, or the ability to imply distance are some of the more common equivalents children use. Some of the equivalents have a relationship to the real world, while some stand for metaphors. The deciphering of metaphors and/or the understanding of pictures varies both individually and culturally. There is frequently an ambiguity in the drawing: more than one way of interpreting it may exist due to the way we perceive the image.

When the developmental stages of children's art are recognized and understood in conjunction with the various styles of learning, then some of the approaches used in art education could be applied. If artistic development is not an automatic consequence of maturation, but rather a process that is affected by the type of experience a child has (Eisner, 1972) then an art program should be able to help develop some of the potential skills of children.

The ability to perceive the environment and to imagine visual possibilities would appear to be most relevant to art education. The child needs to learn how to see the forms he or she creates as part of a total, and to make decisions regarding these relationships; but, it is also of the utmost importance to be aware of the intellectual dimensions of childhood maturation and not to neglect this aspect. Perhaps one of the areas that can be addressed in art education is that of helping the child see or understand shape relationships as well as achieve the ability to perceive that which is subtle.

If the ability to perceive relationships develops as learning occurs in children, and this ability is affected by the variety of experiences they have (Eisner, 1972) then the arts can play a significant role in this aspect of education.

An art program that is sensitive to the needs of children at various stages of development could provide the types of situations necessary for learning to occur in the area of art. A program that assists development through the type of art experiences offered might help children develop the ability to perceive concepts, refine them, and relate them as they are directly related to art education, and for that matter perceptual awareness in general.

\section{REFERENCES}

Bower, T. G. R. The perceptual world of the child. Massachusetts: Harvard University Press, 1977.

Eisner, E. W. Educating artistic vision. New York: MacMillan Publishing Co., Inc., 1972.

Gibson, E. J. Principles of perceptual learning and development. Englewood Cliffs: Prentice-Hall Inc., 1969.

Goodnow, J. Children drawing. Cambridge: Harvard University Press, 1977. 
Kneller, G. F. The art and science of creativity. New York: Holt, Rinehart and Winston, Inc., 1965.

Perkins, D. N. The mind's best work. Massachusetts: Harvard University Press, 1981 .

Pulaski, M. A. S. Understanding Piaget. New York: Harper and Row, 1971. 